\title{
The Reading Tendency of Tibetan Undergraduate Users Based on a Circulation Analysis of Print Books ---A Case of Southwest Minzu University Library
}

\author{
$\mathrm{Ke} \mathrm{Liu}^{1}$ \\ ${ }^{1}$ School of Foreign Languages, Southwest Minzu University, Chengdu, Sichuan 610041, China
}

\begin{abstract}
Based on a circulation analysis of print books borrowed from Southwest Minzu University library by the Tibetan undergraduate users during the academic years from 2014-2015 to 2016-2017, this paper investigates these Tibetan users' reading tendency, which represents an intense interest in Tibetan culture. The results of this study can provide implications for print books collection development so as to meet the needs of the Tibetan users better.
\end{abstract}

Keywords: circulation analysis, Tibetan undergraduate users, reading tendency

\section{Introduction}

The purpose of this study was to investigate the reading tendency of Tibetan undergraduate students by performing a circulation analysis of print books they had borrowed. In this study there were 1369 Tibetan users surveyed, who were all undergraduates from School of Tibetology in Southwest Minzu University (SWUN). SWUN is a university mainly for Chinese minority youth, among whom the number of Tibetans is the largest, and School of Tibetology offers four undergraduate programs, namely, the Tibetan language and culture, ethnology, Tibetan medicine, and cultural industry management. According to the minority bilingual education policy in China, the Tibetan users in this study have received Tibetan-Chinese bilingual education since primary school, and most of them have no problem in speaking and reading Chinese. Some research also shows that in inland colleges and universities most Tibetan students (over 94 percent) are proficient in both Tibetan and Chinese, and only some from remote pastoral areas in Tibetan inhabited regions express they have some difficulty in writing in Chinese [1]. This study made a circulation analysis of the print books that the 1369 Tibetan users of SWUN library had borrowed during the academic years from 2014-2015 to 2016-2017 to explore what their reading tendency was and whether it was relevant to their cultural attitudes.

\subsection{Previous research}

In recent years, there have been studies focused on the evaluation of library collection usage and the investigation of users' reading tendency through the analysis of circulation data of universities libraries, and the results have been applied to improving collection development at universities libraries, providing better service for users and some other important issues. Three recent studies performed at Inner Mongolia Normal University (IMNU) library [2], Anhui Medical University [3], Hengyang Normal University [4] have made an analysis of circulation data of print books to obtain users' reading tendency. The study in IMNU library investigated the ranking list of book categories most checked out, which showed that the leading in the ranking list was literature books, the second was history and geography books, the third was linguistics and text type. The study at Hengyang Normal University library obtained basically the same results, while Anhui Medical University library presented a quite different list, the top in which for 2014-2015 academic year was medical books, the second was literature books, and the third was chemical books. And only one literary book came to the top 5 list of the most borrowed books from 2010 to 2015, coming in fifth. These studies have pointed out that an insight into readers' reading tendency could help put forward some constructive measures to serve readers better. The case study performed in Dalian Fisheries University Library, based on the analysis of the circulation data, explained the circulation characteristics through relevant charts, and discussed the circulation law of paper books in the university library. [5]

\subsection{The contribution of this study}

Previous studies had found that the reading tendency of undergraduate users of universities libraries had much to do with their reading interests and their majors. However, this study emphasized some other factors should be taken into consideration in exploring the reading tendency of undergraduate users, particularly minority undergraduate users, such as their language reading attitudes, their cultural backgrounds, etc., because for Chinese minority undergraduates who have their own native language and culture, their language preference and cultural interests would play an important role in choosing what books to read. This study is the first one to investigate the 
relationship between Tibetan undergraduate users' reading tendency and the influence of Tibetan language and culture through the analysis of print book circulation data. The results of this study can provide implications for print books collection development so as to meet the demands of the Tibetan users better.

\section{Data Analysis}

Southwest Minzu University Library is an academic library housing over 3 million volumes, among which there are over 10,000 volumes of foreign languages, and besides that, it contained more than 50,000 titles of over 20 Chinese minority languages, including Tibetan, Yi, Dai, Kirgiz, Naxi and some other minority languages, serving more than 30,000 undergraduate and graduate students from 56 different ethnic groups in China, and nearly 3000 faculty and staff. In this study the print book circulation data was obtained from SWUN library.

The total number of the print books borrowed by the 1369 Tibetan undergraduate users during the academic years from 2014-2015 to 2016-2017 reached 37086, and the maximum number of books borrowed by one person up to 342. According to Chinese Library Classification (CLC) that has 22 top-level categories, all the borrowed books fall into 19 of them.

Table 1 Circulation data by category (Top 10 by borrowing amount)

\begin{tabular}{lcc}
\hline Category & $\begin{array}{c}\text { No } \\
\text { volumes }\end{array}$ & $\begin{array}{c}\text { Percent } \\
\text { of total }\end{array}$ \\
\hline I ( Literature ) & 14971 & 40.40 \\
B (Philosophy and Religion) & 6389 & 17.23 \\
K (History and Geography) & 6054 & 16.32 \\
H (Languages and Linguistics) & 2939 & 7.92 \\
D (Politics and Law) & 1547 & 4.17 \\
C (Social Sciences) & 1382 & 3.73 \\
G (Culture, Science, Education and Sports) & 791 & 2.13 \\
R (Medicine and Health Sciences) & 735 & 1.98 \\
F (Economics) & 639 & 1.72 \\
J (Art) & 590 & 1.59 \\
\hline
\end{tabular}

As Table 1 shows, the majority of borrowed books are in humanities and social sciences Categories, and in general the Tibetan undergraduates in this study showed less interest in science and engineering books, which probably had something to do with their majors. Table 1 also shows the most borrowed books are in category I that is Literature. This result is the same as those from other studies of the reading tendency of university/college students, e.g. the studies performed in IMNU library and Guizhou Minzu University library [6]. However, different from the findings of the latter studies, this study finds it is philosophy and religion books rather than history or languages books coming in second on the list of top 10 most borrowed subjects.

Of all the 13816 literature books, which does not include literary theory books, there are 7372 volumes falling into the category of Chinese literature, 3667 volumes into
Tibetan literature and 2777 volumes into foreign literature. When considering the number of Tibetan literature books collected in SWUN library is far smaller than that of Chinese or Foreign literature books, the predominance of Tibetan literature books in circulation rate is notable. Figure 1 shows the popularity of foreign literature. American literary works are especially popular with the Tibetan undergraduates, and of Asian literature the most popular are Japanese and Indian literary works.

Table 2 presents a ranked lift of top 5 most borrowed foreign literary works.

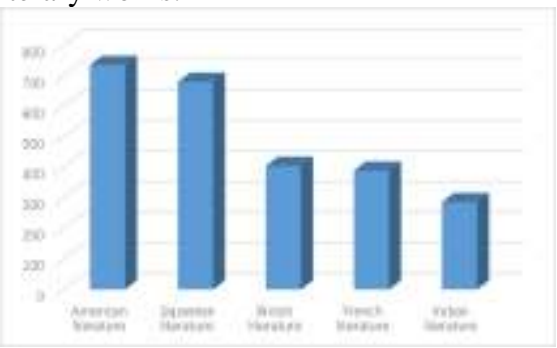

Figure 1 Results by foreign literature as popularity (Top 5)

Table 2. Top 5 most borrowed foreign literary works

1. Ernest Hemingway Selected Letters (1917-1961)

2. War and Peace

3. Italian Fairy Tales

4. Doctor Zhivago

5. Oliver Twist

This study finds that the Tibetan undergraduate users have a keen interest in philosophy, specifically Tibetan Buddhist philosophy, besides a passion for literature. The results show the Tibetan Buddhist philosophy and Tibetan logic books account for 67.2 percent of total borrowing in category B that is Philosophy and Religion. As Figure 2 shows, just a tiny percentage of the total number of books borrowed are English. Considering that there are only 928 circulating Tibetan titles, Tibetan books circulate more rapidly than Chinese books.

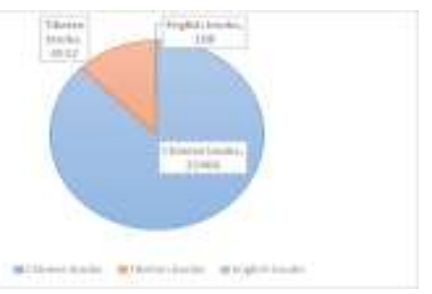

Figure 2 Data by language type

\section{Discussion}

Based on the analysis above, this study argues that the Tibetan undergraduate users have strong awareness of their native culture, which could account for their strong interest in books on Tibetan subjects, including Tibetan literature, philosophy and history, etc. That books in Tibetan language circulate more rapidly than those in Chinese or 
English indicates their fondness of or reliance on their native language. In China minority students have been encouraged to pay great attention to the learning of their native languages and cultures, and for Tibetan undergraduates, an extensive reading in Tibetan will help improve their proficiency in Tibetan and understanding of Tibetan traditional culture. In view of the Tibetan users' greater needs for Tibetan books, it is necessary to increase the Tibetan book collection. It is notable that the number of the Tibetan users' checkouts for English books is too small to match with their passion for American and English literature. This study holds that it is their inadequate English that makes the Tibetan users prefer to reading the Chinese or Tibetan version of foreign literature books rather than their English version, and therefore suggests an increase of Chinese-English or Tibetan-English bilingual version of foreign literary works collection.

Besides the western culture, Indian culture is also popular with the Tibetan undergraduates. According to the results of this study, the books on Indian subjects account for about 1.2 percent of total borrowing. And not only that, the Tibetan Buddhist philosophy and Tibetan logic books account for 11.6 percent of total borrowing, while it is well known that Tibetan Buddhist philosophy and Tibetan logic originated from Indian. Actually, as neighboring countries, China and India, the first and second most populous countries in the world, have maintained cultural exchanges for thousands of years, and the most representative one was the spread of Buddhism from India to China. So this study suggests it be necessary to increase the collection of books on Indian subjects to meet the Tibetan users' great interest in Indian culture.

\section{Conclusion}

Based on a circulation analysis of print books borrowed from Southwest Minzu University (SWUN) library by 1369 Tibetan undergraduate users during the academic years from 2014-2015 to 2016-2017, this study investigates these Tibetan users' reading tendency, which shows they have an intense interest in Tibetan culture, especially Tibetan literature, philosophy and history, etc. Meanwhile, the rapidly circulated Tibetan books indicates their preference for their native language. According to the results of the study, in order to promote the development of the library collection and better meet the needs of the Tibetan college students, it is necessary to increase the paper collection of books, literature and culture.

\section{ACKNOWLEDGMENT}

This work was supported by the Fundamental Research Funds for the Central Universities of China (No. 2019SYB21).

\section{REFERENCES}

[1] Li, Yang and Zhou, Hong (2018). "An Investigation into Tibetan College Students' Language Use in Kunming”. Journal of Liaoning Provincial College of Communications, Vol.20, No.2, pp. 40-42.

[2] Hu, Wuren (2016). “Analysis of Reader's Reading Tendency and Features in University Library under Big Data Environment- A Case of the Library of IMNU". Journal of Inner Mongolia University of Finance and Economics, Vol.14, No.4, pp.144-148.

[3] Zhou, Guozheng and Zhang, Xuemin (2016). "Analysis of the Reading Tendency of Medical University Students Based on the Circulation Data-Taking a Medical University as an Example". Journal of Academic Library and Information Science, Vol.34, No.4, pp.61-64.

[4] Yuan, Hongzhi (2016) "On Library Structure and Reader' S Tendency from the Perspective of Book Circulation Data-Taking the Library of Hengyang Normal University As an Example". Journal of Hengyang Normal University, Vol.37, No.2, pp.170-173.

[5] YU, Xianqian, QU, Hong, and LU Binglian (2018). "Study on Circulation Law of Paper Books in University Library". Agriculture Network Information, No.261, pp.68-71.

[6] Wu, Ling and Jiang, Kaiwu (2013). "Analysis of Readers' Reading Inclination from the Angle of Circulation Data of University Library Collection". Journal of Guizhou Minzu University, No. 141, pp.197-201. 